\title{
Current and Emerging Technologies in Cataract Surgery
}

An Expert Interview with Jennifer Loh

South Florida Vision Associates, Fort Lauderdale, FL, US

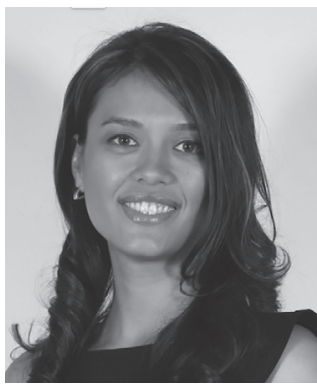

DOI: https://doi.org/10.17925/USOR.2018.11.1.15

\section{Jennifer Loh}

Jennifer Loh, MD is a board-certified ophthalmologist and has been practicing in the south Florida area for the past 6 years. Her focus and passion is on cataract surgery, refractive cataract surgery and dry eye disease. She was recently honored by being named as a Premier Surgeon Top 300 Innovators in Refractive Cataract Surgery and also as one of the Top 50 Rising Stars by The Ophthalmologist.

She currently lectures at ophthalmology meetings nationwide, including the American Academy of Ophthalmology and the American Society for Cataract and Refractive surgery.

\section{Keywords}

Cataract surgery, phacoemulsification, intracameral antibiotics, miLoop, fluidics, hypersonic vitrectomy system

Disclosure: Jennifer Loh has nothing to disclose in relation to this article.

Review Process: This is a short expert interview piece and as such has not undergone the journal's usual peer review process.

Authorship: All named authors meet the International Committee of Medical Journal Editors (ICMJE) criteria for authorship of this manuscript, take responsibility for the integrity of the work as a whole, and have given final approval to the version to be published.

open Access: This article is published under the Creative Commons Attribution Noncommercial License, which permits any noncommercial use, distribution, adaptation, and reproduction provided the original author(s) and source are given appropriate credit. (C) The Authors 2018.

\section{Received: March 17, 2018}

Published Online: March 26, 2018

Citation: US Ophthalmic Review. 2018;11(1):15-16

corresponding Author: Jennifer Loh, South Florida Vision Associates, 2900 W. Cypress Creek Road Suite 4, Fort Lauderdale, FL 33309, US. E: JenniferLohMD@gmail.com

Support: No funding was received in the publication of this article.
$\mathrm{T}$ he ophthalmic community has recently celebrated 50 years of phacoemulsification innovation, and the technology continues to evolve. Recent advances in phacoemulsification techniques and technology have improved surgical outcomes and reduced complications pre and post cataract surgery. However, opinions vary as to which techniques offer the best outcome. In an expert interview, Jennifer Loh, a board-certified ophthalmologist practicing in the south Florida area with considerable expertise in cataract surgery, discussed the most exciting developments and current controversies in phacoemulsification technology.

\section{Q. What are the major unmet needs in current phacoemulsification procedures?}

One of the hottest and most controversial topics in cataract surgery right now is the issue of intracameral antibiotics that can be given at the time of surgery. While multiple studies ${ }^{1,2}$ have proven that intracameral antibiotics are effective at reducing the incidence of endophthalmitis, in the US, there is still no Food and Drug Administration (FDA)-approved intracameral antibiotic. And while there are many compounded versions available, this still comes at a risk for problems such as toxic anterior segment syndrome (TASS) or dilution error.

\section{Q. What were the most exciting developments in phacoemulsification technology in 2017?}

One of the most exciting new technologies in 2017 was the advent of miLOOP'M (Iantech, Inc., Reno, NV, US). MiLoop is a new microsurgical device that uses a nitinol wire loop (the same material that is used in cardiac catheterizations) to dissect the cataract into multiple pieces, while it is still in the capsular bag. This allows for safe disassembly of the cataract with less phacoemulsification energy. It is especially useful with the dense, "leathery" type cataracts that are still very common today in the US and further afield. 


\section{Q. What are the advantages of the fluidics of the comprehensive phaco systems available in the} US?

The phaco systems in the US today provide very stable chambers during cataract surgery. We have options for systems including venturi, peristaltic and combination systems today. I have worked with both the Stellaris (Bausch \& Lomb, Bridgewater, NJ, US) and Centurion ${ }^{\circledR}$ (Alcon, Fort Worth, TX, US) systems and find them both excellent.

\section{Q. What emerging technologies appear promising?} I am very interested in the new hypersonic vitrectomy system, Vitesse ${ }^{\mathrm{TM}}$ by Bausch and Lomb (Bridgewater, NJ, US). Instead of the traditional guillotine cutting system of current vitrectomy systems, the Vitesse liquifies the vitreous using an open port. This technique prevents the vitrector from pulling on the vitreous and causing retinal traction. While most cataract surgeons are luckily not routinely performing vitrectomies, I think having access to this great technology could help improve our results when complications do occur.

\section{Q. For which patients is femtosecond laser technology most useful?}

Femtosecond laser technology is most useful for patients receiving an advanced technology intraocular lens (toric, extra depth of focus, multifocal) and for patients with dense nuclear cataracts. The automatic, well-centered capsulotomy helps with precise lens centration, which can help with the refractive outcome.

1. ESCRS Endophthalmitis Study Group. Prophylaxis of postoperative endophthalmitis following cataract surgery: results of the ESCRS multicenter study and identification of risk factors. J Cataract Refract Surg. 2007;33:978-988

2. Shorstein NH, Winthrop KL, Herrinton $\sqcup$. Decreased postoperative endophthalmitis rate after institution of intracameral antibiotics in a Northern California eye department. J Cataract Refract Surg. 2013;39:8-14. 